\title{
Brinquedotecas Hospitalares: Espaços de Ludicidade e Aprendizagem para Crianças da Educação Infantil
}

\author{
Ordália Alves de Almeida ${ }^{1}$ \\ Thatiana Gonçalves Ignacio \\ Milene Bartolomei Silva ${ }^{3}$
}

\section{RESUMO}

Este artigo resulta de uma pesquisa sobre brinquedotecas hospitalares como espaços de ludicidade e de aprendizagem para crianças da Educação Infantil, que objetivou verificar o perfil das profissionais que atuam nas brinquedotecas hospitalares e quais atividades realizam com as crianças hospitalizadas para aprenderem e desenvolverem-se por meio da ludicidade. Para seu desenvolvimento recorremos a uma revisão de literatura que nos oportunizou aprofundar sobre o referencial teórico básico importante ao desenvolvimento da pesquisa qualitativa realizada, dentre eles destacamos Negrine (2013), Batista; Moreno; Paschoal (2011), dentre outros. As observações foram realizadas na brinquedoteca de um hospital público de Campo Grande/MS, momentos em que observamos as atividades desenvolvidas e as relações estabelecidas entre crianças e professoras. Constatamos que ainda é necessário percorremos um logo caminho para que as práticas de ludicidade nas brinquedotecas hospitalares tornem-se suportes importantes para o desenvolvimento e aprendizagens das crianças.

Palavras-Chave: Crianças. Brinquedoteca hospitalar. Aprendizagem.

\section{ABSTRACT}

This article is the result of research on hospital playrooms as playfulness and learning spaces for children in early childhood education, which aimed to verify the profile of professionals who work in hospital playrooms and what activities they perform with hospitalized children to learn and develop through playfulness. For its development we resorted to a literature

\footnotetext{
${ }^{1}$ Doutora em Educação; Professora titular aposentada da UFMS; Presidente da Câmara de Educação Superior do Conselho Estadual de Educação; Membro do Fórum Permanente de Educação Infantil de MS; Membro da Rede Nacional da Primeira Infância e Professora da Faculdade Insted - Campo Grande-MS

${ }^{2}$ Professora da Secretaria Municipal de Educação de Campo Grande/MS. Graduada em Pedagogia pela Faculdade de Educação da UFMS. Licenciada em Matemática, especialista em Educação Inclusiva e Especial, especialista em Gestão Escolar e Coordenação Pedagógica pelo Centro Universitário Faveni.

${ }^{3}$ Doutora em Educação; Diretora da Faculdade de Educação/UFMS, professora do Curso de Pedagogia da Faculdade de Educação/UFMS; Coordenadora do Grupo de Estudos e Pesquisas sobre Educação, Desenvolvimento Humano e Inclusão (GEPEDHI) CNPq - da linha de pesquisa Educação, Saúde e Práticas Educacionais. Membro do Fórum Permanente de Educação Infantil de MS.
} 
review that gave us the opportunity to deepen the basic theoretical framework important to the development of the qualitative research carried out, among which we highlight Negrine (2013), Batista; Moreno; Paschoal (2011), among others. The observations were made in the playroom of a public hospital in Campo Grande/MS, moments in which we observed the activities developed and the relationships established between children and teachers. We found that it is still necessary to go a short way so that playful practices in hospital playrooms become important supports for the development and learning of children.

Keywords: Children. Hospital playroom. Learning.

\section{Introdução}

Este artigo resulta de uma pesquisa realizada no âmbito da linha de pesquisa sobre Educação, Saúde e Práticas Educacionais do Grupo de Estudos e Pesquisas sobre Desenvolvimento Humano e Inclusão, da Faculdade de Educação, na Universidade Federal de Mato Grosso do Sul (GEPEDHI - UFMS). Nesse grupo realizamos estudos que nos levaram a apropriar de conhecimentos sobre os aspectos a serem valorizadas na prática educativa em classes hospitalares. Especialmente, chamaram-nos a atenção os que tratam sobre o importante papel que a brinquedoteca exerce no processo de recuperação das crianças que frequentam as classes hospitalares.

Dentro desse contexto, objetivamos verificar o perfil das profissionais que atuam nas brinquedotecas hospitalares, bem como as atividades realizadas com as crianças hospitalizadas para aprenderem e desenvolverem-se por meio da atividade lúdica. Observamos que a literatura científica traz contribuições teóricas importantes para que tenhamos uma visão mais ampliada sobre o que vem se realizando nos processos educativos das crianças que se encontram hospitalizadas, frequentando classes hospitalares e as brinquedotecas, sendo utilizadas como espaços que se constituem, nos dias atuais, como espaços de desenvolvimento e aprendizagem, respondendo aos interesses e necessidades dessas mesmas crianças.

Na primeira parte, desenvolvemos uma análise crítica da revisão teórica sobre os artefatos legais que deram sustentação a garantia dos direitos das crianças da Educação Infantil, buscando dimensionar o espaço de direito das crianças que necessitam de atendimentos especializados. Na segunda parte, abordamos sobre o direito que toda criança tem à brincadeira e aprendizagem na brinquedoteca e na classe hospitalar, ressaltando que devem ser criadas as condições propícias para que elas possam ter desenvolvimento pleno enquanto se encontram hospitalizadas.

O sentido do brincar e os processos de humanização no hospital foram objeto da terceira parte, nela buscamos discorrer os aspectos inerentes ao cotidiano das crianças que se encontram hospitalizadas e como as atividades lúdicas são importantes para o desenvolvimento e aprendizagens das crianças de maneira humanizada. E, na última parte, evidenciamos o processo de pesquisa realizado na brinquedoteca hospitalar, ressaltando aspectos resultantes das observações e análises feitas. Especialmente, nos preocupamos em traçar o perfil 
das profissionais que atuam nas brinquedotecas hospitalares e quais atividades realizam com as crianças e se as mesmas se sustentam em um referencial lúdico.

\section{Artefatos Legais para a Garantia dos Direitos das Crianças da Educação Infan- til: Toda a Criança tem Direito a Brincadeira e à Aprendizagem}

No decorrer de nossos estudos realizamos leituras, reflexões e pesquisas a respeito da infância e dos seus direitos, isso se fez necessário para que tivéssemos a dimensão de quais amparos legais tem as crianças que se encontram hospitalizadas. Partimos do princípio de que todas as crianças, em quaisquer condições, devem ter os seus direitos garantidos. Vimos que na Constituição da República Federativa do Brasil de 1988, conforme expressa o art. 208, inc. IV, a criança de 0 até 5 anos tem direito à educação, o que pressupõe que todas as crianças, independentemente de onde estejam têm direito à educação. Ainda, na Carta Magna em seu art. 227, está determinado que:

É dever da família, da sociedade e do Estado assegurar à criança, ao adolescente e ao jovem, com absoluta prioridade, o direito à vida, à saúde, à alimentação, à educação, ao lazer, à profissionalização, à cultura, à dignidade, ao respeito, à liberdade e à convivência familiar e comunitária, além de colocá-los a salvo de toda forma de negligência, discriminação, exploração, violência, crueldade e opressão.

Esses são princípios máximos expressos sobre a garantia do direito das crianças e que orientam todas as ações a serem desencadeadas para a efetivação desses direitos, dentre eles o de garantia de uma saúde plena.

O Estatuto da Criança e do Adolescente (ECA) de 1990 apresenta um conjunto de normas que objetiva a proteção integral da criança e do adolescente. Essa lei é reconhecida no mundo inteiro, em função da abrangência de seus preceitos e pela forma como protege nossas crianças. A saúde da criança também é objeto dessa lei e, segundo o artigo 11:

É assegurado acesso integral às linhas de cuidado voltadas à saúde da criança e do adolescente, por intermédio do Sistema Único de Saúde, observado o princípio da equidade no acesso a ações e serviços para promoção, proteção e recuperação da saúde. (Redação dada pela Lei $n^{\circ} 13.257$, de 2016). § 1o A criança e o adolescente com deficiência serão atendidas, sem discriminação ou segregação, em suas necessidades gerais de saúde e específicas de habilitação e reabilitação. (Redação dada pela Lei $n^{\circ} 13.257$, de 2016); $\S 2^{\circ}$ Incumbe ao poder público fornecer gratuitamente àqueles que necessitarem os medicamentos, próteses e outros recursos relativos ao tratamento, habilitação ou reabilitação.

Como se observa, as garantias legais dão sustentação ao atendimento educacional de crianças que se encontram em classes hospitalares, objeto de nossa investigação. A criança tem o "direito a desfrutar de alguma forma de recreação, programas de educação para 
a saúde, acompanhamento do currículo escolar, durante sua permanência hospitalar" Res. n. 41, de 13/11/1995 - Lei dos Direitos das Crianças e dos Adolescentes Hospitalizados. Tal normativa deixa claro que os direitos constitucionalmente garantidos pelas crianças sofreram desdobramentos que devem resultar em atendimentos de qualidade enquanto estiverem hospitalizadas (art. 9 - Res, n. 41/1995)

A Lei de Diretrizes e Bases n. 9394/1996 (BRASIL, 2017) estabelece que a Educação Infantil é a primeira etapa da Educação Básica. Especialmente, no que se refere à Educação Especial, em contexto da Educação Inclusiva, a Política Nacional de Educação Especial na Perspectiva da Educação Inclusiva (BRASIL, 2008) assegura a escolarização das crianças hospitalizadas, genericamente não é pontual no que se refere às crianças em regime de internação (grifo nosso).

A Política Nacional de Educação Especial (BRASIL, 1994) publicada em 1994, firma a garantia do direito a essa modalidade de ensino e reconhece a importância da classe hospitalar. Ainda, tramita no Senado o Projeto de Lei n $548 / 2015$, que propõe a alteração da redação da Lei 9394/1996, passando a vigorar acrescida do artigo 60-A, que dispõe:

\begin{abstract}
Os sistemas de ensino, mediante ação integrada com o sistema de saúde, oferecerão atendimento educacional especializado a alunos impossibilitados de frequentar as aulas em razão de tratamento de saúde que implique internação hospitalar, atendimento ambulatorial ou permanência prolongada em domicílio. $\S 1^{\circ} \mathrm{O}$ disposto no caput será assegurado por meio de classes hospitalares ou de atendimento pedagógico domiciliar, inclusive para crianças, jovens e adultos não matriculados no sistema educacional local, facilitando seu posterior acesso à escola regular. $\S 2^{\circ}$ Os professores das classes hospitalares e do atendimento pedagógico domiciliar deverão ser habilitados nos termos do art. 62 desta Lei. $\S 3^{\circ} \mathrm{O}$ Conselho Nacional de Educação deliberará sobre as diretrizes operacionais e curriculares para o atendimento educacional especializado em classes hospitalares e no atendimento pedagógico domiciliar.
\end{abstract}

Constatamos que há o firme propósito de se inserir na redação do art. 60 da LDB 9.394/1996, no capítulo Educação Especial, que os sistemas de ensino, em ação integrada com o sistema de saúde, devem oferecer atendimento educacional especializado aos educandos impossibilitados de frequentar as instituições educativas, em função de algum tratamento de saúde que necessitem de regime de internação hospitalar, atendimento ambulatorial ou uma permanência prolongada em domicílio. No entanto, a política deverá assegurar às crianças, por meio de classes hospitalares ou de atendimento pedagógico domiciliar, as efetivas condições para que possam dar continuidade aos seus estudos, independentemente da condição em que se encontram, de maneira que esse atendimento venha a facilitar seu posterior acesso à escola regular. No que diz respeito à profissional que irá atendê-la, a redação é muito vaga, afirmando que deverá ter nível superior, sendo docente em licenciatura plena, não definindo a especificidade de sua ação.

De acordo com o histórico da Associação Brasileira de Brinquedotecas (ABBri) a entidade criou o Curso de Formação de Brinquedistas, desde 1984, ministrando esse curso e 
autorizando outras entidades a ministrá-lo. Segundo informações, em contato com a ABBri, fomos informadas que para fazer o curso de Brinquedista Hospitalar não é necessário ter curso superior, a exigência é ter ensino médio completo. Sendo assim, reiteramos as dúvidas pertinentes à formação profissional tanto no que diz respeito a docente, quanto da brinquedista hospitalar. Negrine (2013) afirma "que tarefas desta dimensão social requerem uma formação consistente [...] em três pilares: formação teórica - formação pedagógica - formação profissional" (p.87).

Para o autor, é necessária uma formação teórica, que priorize o desenvolvimento das crianças por meio do jogo e da aprendizagem, do tempo livre, da recreação e do prazer, situando-as em suas diferenças e seus conhecimentos. Uma formação pedagógica que complete a teórica, atuante no campo lúdico e que se faz na vivência, ou seja, a prática sustentada por reflexão teórica e a formação pessoal, uma abordagem para "configurar que pensamento e corpo são inseparáveis" (NEGRINE, 2013, p. 87). O autor discute a formação da brinquedista hospitalar, propondo repensar a especialização em brinquedista e, também, a formação da pedagoga no âmbito das Universidades, "quando repensamos a questão da formação da educadora infantil percebemos o quanto é importante priorizar, entre outros, o aspecto lúdico nessa formação".

A Resolução n 2 de 11 de setembro de 2001 (BRASIL, 2001) instituiu as Diretrizes Nacionais para a Educação Especial na Educação Básica e a Resolução n 41 de 13 de outubro de 1995 (BRASIL, 1995), do Conselho Nacional dos Direitos da Criança e do Adolescente (CONANDA), aprovou na integra o texto elaborado pela Sociedade Brasileira de Pediatria, que trata dos direitos das crianças e dos adolescentes hospitalizados de maneira específica, bem como a Brinquedoteca Hospitalar, e o brincar no contexto da Pedagogia Hospitalar. Identificamos que as Diretrizes Nacionais para a Educação Especial na Educação Básica, são mais específicas, explicitando que deverá ser assegurado às crianças que, nesse espaço, tenham direito ao convívio com a professora especializada em Educação Especial (BRASIL, 2001).

Ampliando o referencial legal, vimos que a Lei Federal n 11.104/2005 tornou obrigatória a instalação de brinquedotecas em hospitais ou unidades de saúde, que ofereçam atendimento pediátrico no regime de internação dessas crianças pelo tempo que for necessário. Havendo um lugar próprio para a brincadeira é necessário que se garanta profissionais qualificados que possam conduzir e ou mediar as atividades com as crianças e estabelecer, em parceria com a família, relações com elas. Brincar no hospital é um direito da criança na forma de lei. Como podemos observar, hoje temos inúmeros aparatos legais que normatizam sobre o direito de as crianças terem atendimento educacional enquanto se encontram internadas, assim como a necessidade de se ter nas classes hospitalares profissionais qualificadas para atuar nos processos educativos das crianças hospitalizadas. 


\section{Toda Criança tem Direito Brincadeira e Aprendizagem na Brinquedoteca e na Classe Hospitalar: O Sentido do Brincar}

As Brinquedotecas Hospitalares foram criadas muito recentemente, elas datam do século XX, especificamente em 1977, quando pela primeira vez o brinquedo foi reconhecido como terapia. O Ministério da Saúde e Bem-Estar Social da Suécia propôs que a terapia pelo brinquedo fosse um direito reconhecido em prol das necessidades da criança hospitalizada.

No ano de 1984, aconteceu na Bélgica o III Congresso Internacional de Ludotecas, ocasião em que foi apresentada uma pesquisa a respeito do brincar no hospital. Tratava-se de um trabalho desenvolvido pela Cruz Vermelha a favor da humanização em hospitais, em que se evidenciou e se comprovou que brincar ao menos uma vez na semana com crianças em regime de internação era muito importante para a recuperação delas e que deveriam ser realizadas atividades de brincar diariamente, garantindo-se mais tempo para a ludicidade com as crianças. (CUNHA, 2007, p. 72).

Segundo a mesma autora, a partir desse momento foram surgindo as brinquedotecas hospitalares, sendo um dos recursos relevantes na recuperação das crianças. As experiências vividas tornavam suas experiências nos hospitais mais amenas e, ao mesmo tempo, representavam a esperança da cura e lhes proporcionavam segurança, uma vez que as incertezas do ambiente hospitalar geravam, em grande medida, angústia e ansiedade. A segurança citada pode ser proporcionada pelo brinquedo, pelo faz-de-conta, e que muitas vezes levam as crianças a compreenderem a condição em que se encontram.

Cunha (2007, p. 72) destaca que aos principais objetivos para implementação da Brinquedoteca Hospitalar, dentre eles preservar a saúde emocional do paciente nas oportunidades em que o brincar, o brinquedo e o jogo podem criar a possibilidade de fazer colegas ou amigos; facilitar para que a criança se habitue com as situações novas que aconteceram em sua vida; tomar conhecimento no cotidiano do hospital, por meio de situações lúdicas, do tratamento a que estará submetida; favorecer a estimulação do desenvolvimento psicossocial das crianças. A internação a tirará temporariamente, ou interromperá seu convívio com o meio social e cultural privando-lhe de algumas experiências necessárias ao desenvolvimento. E se o período de internação for longo, necessitará de acompanhamento pedagógico no processo de escolarização. E, ainda, dar condições para a família e amigas (os), que irão visitar as crianças, poderem encontrá-las em outro ambiente, desse modo, um jogo, um brinquedo ou uma atividade lúdica poderá tornar esse encontro mais agradável.

Como bem sabemos, muito se discute e se estuda a respeito do brincar, são diversas as possibilidades que se tem de relacionar o brincar, o brinquedo e o jogo ao contexto das brinquedotecas hospitalares, porque essas atividades proporcionam, oportunidades que na prática favorecem o desenvolvimento do processo educativo se o ambiente também for agradável. Fonte de prazer ou não, ao jogar a criança espera um resultado favorável a ela, que Ihe dê prazer, de modo que a atividade complete as suas necessidades. Ao fazermos relação de semelhança entre o olhar que a sociedade apresentava e apresenta hoje "vamos perceber 
que tal visão foi se modificando de acordo com as transformações ocorridas na sociedade ao longo dos anos, [...] não era só a criança considerada um adulto em miniatura, [...] jogos e brincadeiras eram tidos como banais" (BATISTA; MORENO; PASCHOAL, 2011, p. 112).

Valorizar o brincar na área da saúde e reconhecer que criança que brinca enquanto está internada tem maiores condições de aprendizagem é, como já enfatizamos, o objetivo proposto nesse artigo, o brincar essencial à saúde e ao desenvolvimento infantil (CUNHA, 2007, p. 71). Conforme preceitua Negrine (2011, p.18), "o importante é que a ludicidade [...] hoje é estudada como algo fundamental do processo, fazendo com que cada vez mais se produzam estudos de cunho científico [...]". O Brincar é considerado imprescindível no desenvolvimento cognitivo, físico e emocional e na socialização das crianças, sujeitos produtores de cultura e que brincam ao fazer cultura, concordando com Gimenes e Teixeira (2011, p. 20), "quando estruturam um jogo feito com sucata e o divulgam em sua família e pela vizinhança, no lugar onde vivem". Ao brincar a criança torna-se sujeito e vai dando as suas impressões, a respeito do mundo.

Quando a criança adoece, vemos esse episódio como algo incomum, algo não esperado nesse momento da vida, se acometida pela hospitalização pode ficar privada de brincar [..] e cabe aos adultos que estão a sua volta criar as condições para que isso não aconteça, como nos sugere Oliveira (200. p. 27), o brincar "torna-se extremamente relevante em momentos críticos, como os vividos por uma criança no processo de internação", pelo fato de ser uma atividade muito importante para o seu pleno reestabelecimento.

Um hospital apresenta-se como um lugar frio e inóspito, e ao entrar em regime de internação, a criança afasta-se da sua casa, dos seus pertences, dos seus brinquedos, da sua família, dos lugares que frequentava, dos amigos, da instituição educativa frequentada por ela, entre outros. Suas demandas sociais e emocionais ficam comprometidas. Surgem sentimentos de dor, abandono, receio e ansiedade e a culpa aparece como outro elemento que a criança sente no período de adoecimento. Com um ano de idade ou dois a criança pensa estar sendo abandonada, por volta dos quatro ou cinco anos, esse momento vivido é relacionado ao castigo e com dez aos doze anos de idade sente medo da morte e ansiedade (KOVÁCS, 2007, p. 22 - 23); (GIMENES e TEIXEIRA, 2011, p. 198, apud CUNHA e VIEGAS, 2004).

Profissionais que atuam diretamente com ela devem tentar suprir suas necessidades. $\mathrm{E}$ o brincar é a atividade principal e primordial para que a criança se desenvolva plenamente e ao adentrar em um hospital a criança não deixa de ser criança, as atividades lúdicas aparecem como o elemento principal na perspectiva de favorecer a integralidade dessa criança e, como afirma Gimenes (2007, p. 18), o brincar vai facilitar a adaptação do pequeno paciente frente à essa nova situação. Esse autor ainda afirma que o brincar pode "[...] colaborar na elaboração de conflitos no campo afetivo ou cognitivo, acelerar a recuperação psicomotora, caso tenha ocorrido algum dano físico ou neurofisiológico e, até mesmo, quanto ao aspecto social", compreendido no argumento da cultura da infância.

O direito está garantido pela lei, está disposto na literatura, portanto, cabe-nos investigar de que maneira esses direitos efetivamente são garantidos. As Secretarias de Educação 
nem sempre observam esses preceitos legais e não buscam criar relações de parcerias com os gestores dos hospitais para o estabelecimento de planos de ação que possam redundar nesse atendimento, na criação de Brinquedotecas e de Classes Hospitalares. Dos quase mil hospitais pediátricos do Brasil, só 31 possuem brinquedotecas registradas, segundo dados de 2016 da ABBri.

As crianças necessitam de espaços lúdicos amplamente qualificados nas classes hospitalares. Esses espaços, onde o lúdico esteja presente, e que possa ser levado às crianças que se encontram em condições que não podem sair do leito. Espaço este que tenha brinquedos os mais variados possíveis, ao propósito de divertir as crianças como afirma Viegas (2007, p. 50) "com jogos, brincadeiras, brinquedos, teatro, música, pintura, vídeo game, computador, ouvir histórias, leituras, estudos, passeios [...]", que seja um lugar que brincadeiras possam ser realizadas reconhecendo que o mesmo poderá amenizar a sua angústia, sofrimento e facilitar a sua recuperação. Ao falar deste local específico fazemos questão de afirmar que esse local é o do universo da brincadeira e não nos abstemos de ressaltar que todo local pediátrico deva estar preparado para receber essas crianças e que não seja frio, mas que seja humanizado.

Como afirma Oliveira (2007, p. 28) "a Brinquedoteca Hospitalar rompe com a característica temporal contida na rotina da internação, [...], para oferecer um tempo onde os papéis e as funções podem ser divertidos". Apesar do adoecimento, da hospitalização, do embate à doença, esse olhar nos possibilita ampliar o conceito da recuperação da saúde e sobrepor o prazer sobre o sofrimento. Esse lugar próprio para brincar e aprender, como vimos anteriormente, está justificado em lei, especialmente desde 2005, inscrita na Lei Federal 11.104/2005, o que pressupõe que as/os brinquedistas hospitalares são de fundamental importância nesse processo. A Lei existe, mas ela não especifica tecnicamente qual deve ser a estrutura de uma Brinquedoteca Hospitalar e quais profissionais devem atuar nesse espaço, havendo uma necessidade latente de especificar-se, normatizar esse ambiente. Conforme Gimenes e Teixeira (2011, p. 164-167) é importante definir:

O tamanho do espaço físico, mobiliário, piso, tamanho e cores dos brinquedos, higiene, materiais, manutenção, conserto, relação e quantidade mínima de brinquedos, livros e revistas com temas transversais, livros de tombamento, espaços alternativos, cuidados, forma de utilização e responsável.

Tal definição é importante por se tratar do hospital e de características peculiares do ambiente hospitalar. Há normas que não estão na Lei, porém estão dentro das regras de humanização para que seus objetivos sejam atingidos, conforme destacam Viegas e Cunha (2007, p. 101), deve se considerar para um bom projeto de brinquedoteca hospitalar que a direção do hospital necessita dar apoio ao ambiente, a disponibilidade de espaço físico, os recursos materiais disponíveis, a definição de objetivos devem estar coerentes com o contexto hospitalar, se tenha equipe responsável pela Brinquedoteca no ambiente hospitalar e para o bom desenvolvimento das atividades, planejamentos precisam ser elaborados tanto 
do local, quanto das ações, haja interesse dos recursos humanos pelas atividades lúdicas e, ainda que a família deve ser participante e integrante da Brinquedoteca Hospitalar, as regras do hospital precisam ser respeitadas e suas rotinas por vezes são rígidas, a contaminação hospitalar por meio da Brinquedoteca (brinquedos) tem de ser prevenida e a qualidade de vida dos pacientes e da sua família tem que passar por levantamentos a fim de evidenciar seus impactos.

\section{O Sentido do Brincar e os Processos de Humanização no Hospital}

Ao serem hospitalizadas as crianças ficam fragilizadas, a doença as torna diferentes, e ainda, altera a sua rotina. Deixam os espaços que frequentavam e estavam habituadas, saem de suas casas, deixam seus brinquedos e seus pertences, deixam a escola e seus colegas de classe e amigos, deixam seus familiares e passam a conviver com pessoas estranhas, diferentes, desconhecidas até então para ela e assim é preciso acostumar-se com o tempo e o espaço inexplorado e participar de uma outra rotina, no Hospital.

Viegas (2007, p. 49) afirma que "a doença tornou a criança também diferente, fraca e sensível, é difícil aceitar a dor das injeções, picadas para coleta de exames, o sono interrompido para a verificação de temperatura[...]". As brincadeiras, o brinquedo, oportunizam às crianças transformarem esse inexplorado em habitual, essa transformação permite às crianças intensificarem o vivido ou alterá-lo. Gimenes e Teixeira (2011, p. 84), por sua vez, argumentam que, "o brinquedo é um meio de transferir e transformar a realidade interna e externa da criança". Elas necessitam de um atendimento humanizado, o que nos remete a ressignificar os olhares voltados a elas na condição de paciente.

A Brinquedoteca Hospitalar constitui-se, portanto, em um recurso de relevância para a vida das crianças hospitalizadas, é o espaço que pode lhes oportunizar a lidar de forma mais amena com a doença. O Brincar, atividade característica da criança, necessária ao seu desenvolvimento cognitivo, psicológico e social, nos remete à importância do Hospital, quando consideramos os aspectos inerentes ao desenvolvimento infantil, além dos clínicos, além da doença.

Nas palavras de Oliveira (2007, p. 27) brincar "pode ser considerado como fonte de adaptação e instrumento de formação, manutenção e recuperação da saúde". Ao relacionar o brincar com a saúde, ao relacionar as crianças e o brincar aos momentos de internação na tentativa de ajudá-las a vencerem a ansiedade, momentos que podem se transformar em críticos e desgastantes para elas e que, ainda, dependem do seu estado de saúde. O tempo que precisaram estar internadas, como foram recebidas no hospital, como é esse ambiente e, também, como seus familiares lidam com as situações, muitas vezes consideradas inesperadas nessa fase do desenvolvimento humano, vão exigir a criação de contextos mais saudáveis de vida para as crianças.

É como se perdessem a identidade, ao afastarem-se do seio familiar. Entram na rotina do tempo e do espaço hospitalar e necessitam amadurecer mais rápido, o sofrimento as fa- 
zem amadurecer mais rápido, mas não podemos perder de vista que é necessário respeitar a subjetividade das crianças e seus familiares, buscando uma abordagem humanizada para o enfrentamento dessa nova situação no contexto familiar. Há diversas maneiras de entender essa prática, como refere Viegas (2007, p. 11), "[...] sendo cuidada em um ambiente estranho, o hospital, frequentemente com muita ciência e tecnologia, mas nem sempre com o carinho necessário".

Mais do que uma atitude, é preciso viver a humanização na sensibilidade, é necessário respeitar àquele pequeno paciente que foi acometido por uma doença como pessoa, a hospitalização por longo tempo, por vezes indeterminado ou recorrente pode causar o que chamamos de nanismo psicossocial por estresse extremo. Nas palavras de Viegas (2007, p. 50) "a criança para de crescer. Como toda vivência, esse também pode ser o momento de amadurecimento emocional, o que nem sempre acontece, ficando traumas, às vezes pelo resto da vida". A família é parte essencial de todo esse processo, muitas vezes em função do adoecimento do filho, necessita alterar a sua rotina, sendo influenciada de maneira direta e indireta.

Brincando as crianças humanizam-se, brincando em grupo socializam-se, aprendem a compreender o espaço da outra e as regras. Repetindo as brincadeiras, imprimem nas mesmas suas singularidades, ao imprimir suas particularidades vão criando histórias, as suas próprias e a das outras. Dessa forma concordamos com Gimenes (2007, p. 16) quando afirma que "[...] o brincar passa a ser considerado um agente facilitador excelente de transmissão cultural".

No espaço da brinquedoteca, os pequenos pacientes necessitam ser acompanhados por uma profissional que possua formação teórica pertinente e peculiaridades na sua formação profissional e de sujeito. A brinquedista hospitalar atenderá crianças com diversas particularidades e deverá prestar atenção e respeito a cada uma delas. De acordo com Cunha (2007, p. 75), deverá conhecer os motivos que as levaram ao Hospital, a enfermidade e considerar as suas condições orgânicas em função do tratamento que estão submetidas, causando-Ihes limitações, assim como as suas condições físicas. Equilíbrio emocional para não as submeter a condição de vítimas e, também, não as superestimar. O importante é ser uma presença receptiva, que as crianças sintam que profissional estará ao lado delas a fim de lhes acolher.

Azevedo (2011, p. 85) relata a respeito de uma pesquisa de Santos e Bichara (2001) sobre as atividades lúdicas em uma brinquedoteca hospitalar e a influência sobre os pacientes, evidenciando que $57 \%$ dos episódios assistidos no ambiente foram silenciosos. Fortuna (2007, p. 41), apoiando-se em Dolto (1999), relata que para uma criança é interessante "brincar de forma silenciosa". Argumenta que "angústia não se combate com angústia", porém o silêncio é necessário para preservar a intimidade, ser tranquilizador e momento de reestabelecer o equilíbrio e entender a realidade que a cerca. Adultos parecem temer o vazio, mas com um brinquedo não estão sozinhas.

A profissional tem que auxiliar as crianças, de modo a provocar e facilitar uma ressigni- 
ficação da aprendizagem por meio do brincar, porém necessita de uma atitude elaborada e estudada para que elas liberem anseios e sentimentos, uma vez que se encontram oprimidas pela condição da hospitalização, que "produz sentimento de desvalorização em relação às outras crianças" (FORTUNA, 2007, p. 37).

A Brinquedoteca Hospitalar é o espaço onde poderá ter opção de escolha de querer brincar ou "não" e escolher o brinquedo ou jogo que quiser, dentre os que estão disponíveis, "As escolhas das crianças, se forem realmente livres, podem nos surpreender e merecem que reflitamos sobre elas. De onde se originam? Que necessidades provocaram? Quem poderia adivinhá-las?" (CUNHA, 2011, p. 30). Essa mesma autora afirma que não podemos saber todos os sentimentos que afetam essas crianças, mas brincar certamente ajudará a superá-los. Mas também é preciso que sejam bem variadas as oportunidades ao brincar e as opções de escolha Ihes sejam asseguradas.

Será o momento de reelaborarem a esperança na cura do tratamento e da volta para casa. Interação da realidade com a fantasia a fim de aliviar o sofrimento da internação. Brincar mantém as crianças conectadas às suas histórias de vida, porém o essencial é que o lúdico ajude a criar um vínculo humano, como afirma Oliveira (2007, p. 30), seja "voltado para a saúde entre a criança, a família e a equipe de saúde, dentro do ambiente hospitalar".

O papel exercido por profissionais nesse espaço é relevante para estimular a capacidade expressiva, espaço para a comunicação, interpretação de sentimentos e de necessidades e da estruturação de relações mais positivas com o ambiente. Os pequenos pacientes e suas famílias necessitam ser assistidos integralmente e as profissionais farão o papel de mediadoras da atividade lúdica, para que a brincadeira aconteça, não interferindo, a não ser que as crianças peçam. Respeitando e reconhecendo esse espaço de experiência, em que as crianças se constroem brincando e se expressam por meio da atividade lúdica.

A presença da docente no espaço hospitalar deve garantir as crianças a continuidade do processo de escolarização por estarem afastadas da escola e o lúdico neste processo torna-se de fundamental importância. A docente participa de uma equipe multidisciplinar em que todos deverão ter a sensibilidade necessária para oferecer aos pequenos pacientes respeito e buscar, apesar da doença, como nos demonstra Viegas (2007, p. 49) Ihes proporcionar "uma melhor qualidade de vida", isto é humanização. O incentivo ao brincar, que deve estar presente na Brinquedoteca Hospitalar, rompe com o modelo tradicional, trazendo uma nova perspectiva de valorização das crianças que adoecem, das famílias e das profissionais da equipe multidisciplinar que lhes atendem.

\section{Vivências Empíricas no Processo de Humanização das Crianças em Brinque- doteca Hospitalar}

A pedagogia hospitalar e o brincar fundamentaram nosso interesse pela pesquisa, por se tratar de um assunto com o qual convivemos em nossa prática e por ser uma área de atuação da pedagogia considerada não formal, resultante do estabelecimento de uma parceria 
entre escola e hospital, com o intuito de colaborar no processo de escolarização das crianças hospitalizadas em regime de internação, nas unidades hospitalares de pediatria. Para tanto, iniciamos observando o que determina a Resolução $n^{\circ}$ 196/1996, do Conselho Nacional de Saúde, Lei 8080/1990, submetendo nossa pesquisa ao Comitê de Ética em Pesquisa (CEP) da UFMS, sendo autorizada a sua realização, segundo os parâmetros éticos de uma pesquisa científica, que envolva seres humanos, sob o número 62205216.6.0000.0021 do Certificado de Apresentação para Apreciação Ética (CAAE).

Recorremos a uma metodologia que se sustentou na revisão de literatura, de maneira a ampliar o nosso conhecimento sobre a temática em questão e subsidiar as discussões da coleta de dados e na análise qualitativa de observações realizadas em brinquedoteca de um hospital público, na ala da pediatria, que atende crianças de 0 a 12 anos, em Campo Grande no estado do Mato Grosso do Sul.

A pesquisa de campo foi realizada com o intuito de conhecer as crianças na faixa etária de 0 a 6 anos de idade e como a participação nas atividades lúdicas-pedagógicas, desenvolvidas no espaço brinquedoteca da Unidade de Internação desse hospital público, contribuem para o desenvolvimento e aprendizagens dessas crianças. Envolvemos as docentes desta unidade, a fim de saber como e, respectivamente, quais atividades lúdicas-pedagógicas são desenvolvidas nesse espaço, qual o papel da professora e a formação delas. Para tanto recorremos a observação participante e entrevista aberta. As observações e coletas de dados foram realizadas entre os meses de outubro de 2017 a maio de 2018. As conversas informais com professoras da rede estadual que trabalham no hospital deram início à pesquisa.

Na pesquisa qualitativa "as estratégias mais representativas da investigação qualitativa, e aquelas que melhor ilustram as características anteriormente referidas, são a observação participante e a entrevista em profundidade" (BOGDAN; BIKLEN, 1994, p. 16). Nos primeiros dias de observação nos mantivemos mais distante, esperando que as crianças percebessem a nossa presença e aceitassem a nossa entrada no ambiente, até que com o passar dos dias isso foi acontecendo.

Por meio da observação participante conseguimos adentrar no ambiente, lócus da pesquisa, e produzimos diários de campo. Conforme Bogdan e Biklen (1994, p.150) afirmam, “[...] o investigador registrará ideias, estratégias, reflexões e palpites, bem como os padrões que emergem". E continuam, "isto são as notas de campo, o relato escrito daquilo que o investigador ouve, vê, experiência, e pensa no decurso da recolha e refletindo sobre os dados de um estudo qualitativo". Entrevistas foram realizadas, com o objetivo de saber o que pensam os sujeitos, nas suas diferentes perspectivas pessoais. De acordo com Bogdan e Biklen (1994, p. 138) faz-se necessário compreender os comportamentos das pessoas, estes, os quais não podem ser mensuráveis.

A Brinquedoteca do hospital observado divide seu "espaço físico" com a Classe Hospitalar, constatamos que o mesmo espaço físico é estruturado em dois ambientes distintos e com objetivos diferentes. As atividades desenvolvidas pelas pedagogas com as crianças pequenas acontecem no espaço físico Brinquedoteca, pois o ambiente conta com mesas e 
cadeiras adequadas ao tamanho das crianças, sempre acompanhadas das mães, após as atividades orientadas, as mesmas podem continuar no local, brincando.

É uma sala pequena, ao final do corredor da Unidade de Pediatria, corredor com as paredes decoradas com imagens infantis nas cores verde claro, diferenciando-se das outras alas do Hospital. As portas dos quartos, que dão para o corredor da enfermaria, têm uma parte que é transparente, portanto, quando passamos por elas podemos ver todas as crianças e, desse modo, observar que brincam em seus leitos com brinquedos trazidos de casa por suas mães, se permitido pelo médico, ou com algum brinquedo da Brinquedoteca que as mães tenham solicitado às professoras da Classe Hospitalar/ Brinquedoteca.

As dimensões do espaço são adequadas à quantidade de crianças que passam por ali no decorrer do dia. Temos ciência da Lei Federal 11.104, de 21 de março de 2005, que torna obrigatória a efetivação das brinquedotecas em hospitais, porém, a referida Lei, não normatiza qual deve ser o tamanho do seu espaço físico, a Brinquedoteca Hospitalar não é especificada tecnicamente nesse documento, ficando a critério da Instituição, porém existem as regras que não estão na Lei, mas estão nas regras da humanização. Seu espaço físico encontra-se em processo de ressignificação, havendo uma divergência também quanto aos aspectos físicos do espaço em relação ao documento do Ministério da Educação publicado pela extinta Secretaria de Educação Especial (SEESP) em 2002, intitulado "Classe hospitalar e atendimento pedagógico domiciliar: estratégias e orientações", documento esse que, segundo nosso ponto de vista, necessita ser reelaborado.

Quando necessário, as professoras utilizam o espaço da Brinquedoteca, pois o tamanho das mesas e cadeiras é adequado às crianças, para o desenvolvimento de atividades pelas professoras, da rede estadual de ensino, porém o atendimento educacional também acontece nos leitos, ou no quarto de isolamento se as condições da criança assim exigirem, e sempre de acordo com a equipe multidisciplinar. Esporadicamente, é pedido pelo médico um brinquedo para aliviar a angústia da criança durante algum procedimento clínico. As mães acompanhantes também pedem brinquedos quando as crianças estão chorando para aliviar o sofrimento das mesmas.

O espaço físico destinado a Brinquedoteca tem poucos brinquedos, segundo informações encontram-se em processo de aquisição e seleção. As bonecas, carrinhos, casinhas e alguns jogos estão dispostos em um armário, o mesmo onde ficam os livros de literatura utilizados na Brinquedoteca, doados pela comunidade. Uma televisão, acoplada à parede, acima de uma prateleira, não sendo utilizada durante o período observado. Observamos que esse é o lugar onde as crianças gostam muito de estar, mesmo que seja só por estar ali. No espaço destinado a Brinquedoteca acontecem atividades de livre brincar e atividades orientadas, sendo acompanhadas pela equipe de professoras Pedagogas e outras com formação em outras Licenciaturas.

Uma das professoras relatou-nos que sentiu a necessidade em fazer a pós-graduação em Pedagogia Hospitalar para conhecer os processos hospitalares, como a parte administrativa, prevenção de doenças das docentes e das crianças-alunas/os, higiene e funcionamento 
hospitalar em geral. Ressaltou que o tempo de permanência com cada estudante faz-se em média em 40 minutos e acontece no período da manhã, após a recolha de exames e do café da manhã. Esse tempo não é fixo, pois por se tratar de um ambiente peculiar, acontecem adversidades, principalmente em relação ao estado de saúde dessas crianças em regime de internação, ela atende à Brinquedoteca Hospitalar quando necessário.

Em relação à metodologia utilizada, relatou-nos que recorre ao método tradicional, durante o processo de ensino aprendizagem e, ao observar que aquele método não é o suficiente, utiliza-se de outro, o "lúdico pedagogizado", conforme expressou. Observa-se que a escolarização é vista com um processo separado da brincadeira, e que a mesma vem depois. Utilizam-se da brincadeira como atrativo, primeiro chamam as crianças para brincarem, e após pouco tempo dizem "agora é hora de estudar", evidenciando a dicotomia entre lúdico e a aprendizagem. No período de observação e por meio da entrevista aberta verificamos que a Brinquedoteca fica sob a responsabilidade das professoras de segunda a sexta-feira, no período da manhã e tarde, dividindo seu espaço com a Classe Hospitalar. Permanece aberta aos sábados, domingos e feriados, porém sem a supervisão das professoras, para que as crianças tenham acesso.

O período de maior movimento do espaço físico é o matutino, utilizado como Classe Hospitalar tanto pelas professoras Pedagogas, quanto pelas Professoras das Licenciaturas. O tempo utilizado para o desenvolvimento das atividades é em média de 40 minutos. Enquanto as aulas acontecem, a Brinquedoteca Hospitalar também está em funcionamento, sendo as crianças atendidas pelas Pedagogas, sem tempo delimitado, se essas não tiverem que realizar atividades orientadas e também pelas professoras de outras licenciaturas. Durante a observação verificamos que o espaço físico é o local onde as acompanhantes também gostam de estar, geralmente são mães que ficam ali com suas/seus filhas/os para permanecerem conectados a sua história de vida.

As atividades lúdicas desenvolvidas na Brinquedoteca acompanhadas pelas professoras da equipe e incluem desenhos, pinturas, recortes e brincadeiras, geralmente após as aulas. Brincadeiras com bonecas, carrinhos, brinquedos de montar, quebra cabeças e jogos de raciocínio. Não há divisão dos brinquedos por idade, mas há brinquedos para as variadas idades, nas prateleiras mais baixas estão àqueles para as crianças pequenas, elas escolhem os brinquedos que mais gostam. Não há monitoramento das atividades lúdicas por uma profissional responsável, por isso a equipe de saúde entende ser melhor não permitir a troca de brinquedos entre as crianças, também não se utilizam de brinquedos durante a realização de procedimentos clínicos.

A professora responsável pela Brinquedoteca faz anotações da criança, a atividade que realizou com a mesma no que diz respeito ao acompanhamento pedagógico, o tempo em que permaneceu no espaço, se esteve sozinha ou acompanhada, além de uma ficha com o nome da criança, idade, escolaridade e o quarto em que se encontra internada. As atividades desenvolvidas na Classe Hospitalar são diversas, mas a prática pedagógica tradicional é mantida, havendo uma ausência de um contexto lúdico. Jogos são utilizados, no entanto, há uma 
preocupação maior com a escolarização. Vimos que o lúdico não ampara, ou muito pouco acontece nas relações de ensino-aprendizagem, parece haver uma fragilidade teórica sobre a importância do lúdico no processo educativo das crianças e isso influencia diretamente na prática pedagógica.

Procuramos traduzir a ação de uma professora, responsável pela Classe Hospitalar, que utiliza a brincadeira como algo para atrair as crianças, porém depois fala que elas estão ali para estudar. A coordenadora geral da Classe Hospitalar também nos disse que a prioridade são as aulas e não a Brinquedoteca, a profissional avalia o nível escolar das crianças, a fim de direcionar as atividades, e a depender da resposta da criança, a atividade poderá ser conduzida por meio de um jogo pedagógico em seguida.

As crianças de 0 a 3 anos não são atendidas na Classe Hospitalar, elas vão à Brinquedoteca levadas pelas mães para brincar, algumas choram muito e não querem ir para seus quartos quando é chegada a hora de sair. Geralmente, a criança vai a Brinquedoteca com sua mãe, a professora que no referido momento encontra-se na Brinquedoteca orienta a respeito das normas do ambiente e horários, caso aquele seja o primeiro dia no ambiente. $\mathrm{O}$ fato de a mãe estar com a criança naquele espaço traz a possibilidade de fortalecer o afeto entre os mesmos e também de manter vínculos com as suas histórias de vida, surge a possibilidade da socialização, entre acompanhantes e com a professora presente no ambiente.

Na Brinquedoteca do referido Hospital, as crianças têm a liberdade de escolher os brinquedos que mais lhes atraem. Elas também demonstraram cuidado com os brinquedos, guardando-os ao final da brincadeira. No período de observação das crianças, as brincadeiras espontaneamente, como se esquecessem temporariamente da sua condição de saúde.

Verificamos que as crianças, na maior parte do período observado, brincam com a sua mãe ou, apenas com o brinquedo. O Espaço da Brinquedoteca Hospitalar é destinado a estimular as crianças e seus acompanhantes a brincarem, além de brincar com os brinquedos e jogos, brincam os pares também. As crianças demonstram carinho pelas professoras da brinquedoteca/classe hospitalar e estabelecem vínculos afetivos com as mesmas. Solicitam que peguem jogos para elas, que forneçam papel para fazerem algum desenho, entre outros. Algumas gostam de contar fatos que consideram interessantes. As professoras da brinquedoteca hospitalar demonstram cuidados com as crianças. Vimos, portanto, que apesar das limitações do espaço e da pequena quantidade de brinquedos oferecidos às crianças, há o estabelecimento de relações entre as crianças e os professores por elas responsáveis.

\section{Algumas Considerações que não são Finais}

No Estado de Mato Grosso do Sul - Campo Grande, a Secretaria de Estado de Educação (SED-MS) contrata professoras e professores, pedagogos e das áreas específicas de conhecimento para atuarem nas brinquedotecas e nas classes hospitalares desde a Educação Infantil, Ensino Fundamental I e II e Ensino Médio. As docentes são contratadas para atuar no Hospital, em classe hospitalar e não na brinquedoteca hospitalar. Para que o atendimento 
pedagógico educacional se efetue, a SED-MS firma convênio com o hospital e o desenvolvimento do trabalho é acompanhado pelo Centro Estadual de Educação Especial e Inclusiva (CEESPI), pelo Núcleo de Classe Hospitalar/ SED/MS e pela Coordenadoria de Políticas para Educação Especial (COPESP), responsabilizando-se em dar a continuidade dos estudos de crianças-alunos matriculados, ou, não, em ensino regular das escolas municipais, estaduais, particulares ou especiais de Campo Grande/MS e também no interior do MS.

As professoras são contratadas pela SED-MS e não são funcionárias do hospital, mas o espaço físico é cedido pelo hospital e, portanto, consideramos esse espaço físico em processo de transformação e de ressignificação. Para atuar em classe hospitalar/brinquedoteca hospitalar é necessário ter especialização, e é relevante ter em Educação Especial. As Diretrizes Nacionais para a Educação Especial na Educação Básica, são mais específicas, em relação à profissional que irá atuar em ambiente hospitalar, conforme a redação, deverá ser assegurado aos educandos nesse espaço que tenham direito à professora especializado em Educação Especial (BRASIL, 2001). Mas as profissionais atuantes têm suas particularidades na formação, vistos à necessidade própria do ambiente. Ressaltamos que é muito importante que esses profissionais tenham a formação específica para atuar apenas na brinquedoteca hospitalar.

Muitas crianças em regime de internação estão matriculadas em escolas regulares, que atuam na perspectiva da educação inclusiva, uma vez que são amparadas por Lei, tendo o direito de continuar seus estudos, estando hospitalizadas, assim, passam ser vinculados temporariamente a educação especial, apesar de a Lei não especificar as crianças hospitalizadas. Há uma dicotomia referente a identidade das classes hospitalares, pois muitas crianças atendidas não se encaixam no descrito público-alvo da educação especial.

A escolarização das crianças em regime de internação é muito semelhante à escola formal. Ao ampliarmos a visão sobre o que é considerado formal, ressaltamos que as práticas pedagógicas existentes na escola do hospital são amparadas por Documentos Legais da Educação Básica, entretanto há uma ausência de valorização dos processos lúdicos nas práticas pedagógicas observadas. Esse currículo é flexibilizado, no que diz respeito às peculiaridades do ambiente, mas não no que diz respeito às metodologias, é aquele mesmo utilizado pela escola regular que está fora do hospital, um currículo tradicional.

Nosso questionamento refere-se ao ambiente hospitalar e tais práticas produzidas nele. Esse posicionamento tradicional, na maior parte do período observado, não se adequa ao contexto, observamos cópias estereotipadas, e não estratégias e recursos outros que as crianças se apropriem da leitura e da escrita, mais prazerosa para o contexto. Constatamos que ainda é necessário percorremos um logo caminho para que as práticas de ludicidade nas brinquedotecas hospitalares se tornem suportes importantes para o desenvolvimento e aprendizagens das crianças. 


\section{Referências Bibliográficas}

AZEVEDO, Antonia Cristina Peluso de. Brinquedoteca no diagnóstico e intervenção em dificuldades escolares. Edição Especial. Campinas, São Paulo: Editora Alínea, 2011.

BATISTA, CleideVictor Mussini; MORENO, Gilmara Lupion; PASCHOAL, Jaqueline Delgado. $(\mathrm{Re})$ Pensando a Prática do Educador Infantil. In: SANTOS, Santa Marli Pires dos Santos (org.). Brinquedoteca: a criança, o adulto e o lúdico. 7. ed. Petrópolis, RJ: Editora Vozes, 2011. BRASIL. CNE. Diretrizes Nacionais para a Educação Especial na Educação Básica. Brasília: MEC, 2001.

BRASIL. MEC. SEE. Política Nacional de Educação Especial. Brasília, MEC/SEESP, 1994.

BRASIL. Decreto $n^{\circ}$ 7.611, de 17/11/2011. A educação especial, o atendimento educacional especializado e dá outras providências. DOU, Brasília, DF, 18 nov. 2011b. Disponível em <http:// www.planalto.gov.br/ccivil_03/_ato2011-2014/2011/decreto/d7611.htm>. Acesso em: 08/02/ 2018.

BRASIL. MEC. Classe hospitalar e atendimento pedagógico domiciliar: estratégias e orientações. Secretaria de Educação Especial. Brasília, DF. SEESP, 2002.

BRASIL. Lei $n^{\circ} .11 .104$, de 21/03/2005. Obrigatoriedade de instalação de brinquedotecas nas unidades de saúde que ofereçam atendimento pediátrico em regime de internação. Disponível em <http://www.planalto.gov.br/ccivil_03/_Ato2004-2006/2005/Lei/L11104.htm>. Acesso em 30 de out. 2017.

BRASIL. Lei $n^{\circ}$. 8080. Condições para a promoção, proteção e recuperação da saúde, a organização e o funcionamento dos serviços correspondentes e dá outras providências. Brasília, DF: Senado, 1990. (COMITE DE ÉTICA)

BOGDAN, Robert; BIKLEN, Sari. Investigação qualitativa em educação. Porto: Porto Editora, 1994.

CUNHA, Nylse Helena da Silva. Brinquedista Hospitalar. In: VIEGAS, D. (Org.). Brinquedoteca hospitalar: Isto é humanização. 2. ed. Rio de Janeiro: Wak, 2007.

CUNHA, Nylse Helena da Silva. O Brincar e as Necessidades Especiais. In SANTOS, Santa Marli Pires dos Santos (org.). Brinquedoteca: a criança, o adulto e o lúdico. 7. ed. Petrópolis, RJ: Editora Vozes, 2011.

FORTUNA, Tânia Ramos. Brincar, Viver e Aprender: Educação e Ludicidade no Hospital. In: VIEGAS, Drauzio. (Org.). Brinquedoteca hospitalar: Isto é humanização. 2. ed. Rio de Janeiro: 
Wak, 2007.

GIMENES, Beatriz Piccolo. O Brincar e a Saúde Mental. In: Brinquedoteca hospitalar: Isto é humanização. 2. ed. Rio de Janeiro: Wak, 2007.

KOVÁCS, Maria Julia. A Criança e a Morte. In: VIEGAS, Drauzio. (Org.). Brinquedoteca hospitalar: Isto é humanização. 2. ed. Rio de Janeiro: Wak, 2007.

NEGRINE, Airton. O Lúdico no Contexto da Vida Humana: Da Primeira Infância à Terceira Idade. In: SANTOS, Santa Marli Pires dos Santos (org.). Brinquedoteca: a criança, o adulto e o lúdico. 7. ed. Petrópolis, RJ: Editora Vozes, 2011.

OLIVEIRA, Lecila Duarte Barbosa. A brinquedoteca hospitalar como fator de promoção no desenvolvimento infantil: relato de experiência. Revista Brasileira Crescimento Desenvolvimento Humano. 2009; 19(2): 306-312.

OLIVEIRA, Vera Barros de. O Lúdico na Realidade Hospitalar. In: VIEGAS, Drauzio. (Org.). Brinquedoteca hospitalar: Isto é humanização. 2. ed. Rio de Janeiro: Wak, 2007.

SANTOS, Santa Marli Pires dos Santos (org.). Brinquedoteca: a criança, o adulto e o lúdico. 7. ed. Petrópolis, RJ: Editora Vozes, 2011.

VIEGAS, Drauzio. (Org.). Brinquedoteca hospitalar: Isto é humanização. 2. ed. Rio de Janeiro: Wak, 2007. 